\title{
Near-sudden unexpected death in a patient with epilepsy undergoing hemodialysis: a case report
}

\author{
Satoki Hatano ${ }^{1} \cdot$ Go Kanzaki $^{1,2}$ (1) $\cdot$ Hirokazu Marumoto ${ }^{2} \cdot$ Takahito Niikura $^{1,2} \cdot$ Kosuke Honda $^{1,2} \cdot$ Yasuyuki Nakada ${ }^{1,2}$. \\ Masayo Morita ${ }^{1} \cdot$ Takashi Hasegawa $^{1} \cdot$ Takashi Yokoo $^{2}$
}

Received: 27 July 2020 / Accepted: 18 May 2021 / Published online: 26 May 2021

(c) Japanese Society of Nephrology 2021

\begin{abstract}
Sudden unexpected death in epilepsy (SUDEP) has been defined as a sudden/unexpected, witnessed/unwitnessed, nontraumatic, and nondrowning death in epileptic patients with/without seizure evidence and documented status epilepticus. Identified as the leading cause of epilepsy-related deaths, SUDEP cases are highly unrecognized and underreported due to diagnostic difficulty. We report a case of a successfully revived hemodialysis patient who developed cardiopulmonary arrest after a witnessed convulsive seizure. Electroencephalogram revealed epileptic abnormalities. Therefore, this case could be seizure-induced cardiopulmonary arrest and near-SUDEP. Hence, the possibility of SUDEP should be considered even in hemodialysis patients having conventional coronary risk factors for sudden cardiac death.
\end{abstract}

Keywords Sudden unexpected death in epilepsy (SUDEP) $\cdot$ Hemodialysis (HD) $\cdot$ Seizure $\cdot$ Cardiopulmonary arrest (CPA)

\section{Introduction}

Sudden death (SD) is considered a common occurrence in patients undergoing hemodialysis (HD) [1]. Recent studies show that $13-16 \%$ of all deaths in Japanese HD patients were due to $\mathrm{SD}[2,3]$; this indicates that SD is now more common even in the Japanese dialysis clinical setting than previously believed [4]. HD patients are determined to be at an increased risk for SD due to several reasons. Although these patients often suffer from coronary artery disease and cardiomyopathy, which are considered well-known risk factors for SD [5], there is still a lack of evidence directly supporting their relationship with SD due to the difficulty in determining the cause of SD.

Sudden unexpected death in epilepsy (SUDEP) typically refers to a sudden, unexpected, witnessed or unwitnessed, nontraumatic, and nondrowning death, occurring in healthy conditions, in an individual with epilepsy with or without

Go Kanzaki

g-kanzaki@jikei.ac.jp

1 Department of Internal Medicine, Atsugi City Hospital, Kanagawa, Japan

2 Division of Nephrology and Hypertension, Department of Internal Medicine, The Jikei University School of Medicine, Minato-ku, Tokyo 105-8461, Japan evidence for a seizure and excluding a documented status epilepticus, and where the postmortem examination does not disclose a toxicological or anatomic cause for the death [6]. SUDEP is considered the primary but rare cause of deaths in patients with epilepsy [7]. The incidence of SUDEP has been reported to be $1.20 / 1000$ person-years [8,9], with only a few cases of SUDEP being reported in HD patients till date [10].

Herein, we report a rare case of witnessed SUDEP in an HD patient who was successfully revived without complications via cardiopulmonary resuscitation (CPR).

\section{Case report}

A 40-year-old male patient presented to the emergency department after a CPR was performed on him due to cardiopulmonary arrest (CPA) that occurred after a seizure, witnessed by his friend via videophone. He had been undergoing regular HD at another clinic for 3 years due to type 1 diabetes, and his condition had been reported to be stable the day before. He received insulin degludec, insulin aspart, furosemide, precipitated calcium carbonate, dried ferrous sulfate, ascorbic acid and calcium pantothenate, ezetimibe, mosapride citrate hydrate, antibiotic-resistant lactic acid bacteria, senna pods, sennoside, and fexofenadine 
hydrochloride. There was no history of oral theophylline or high caffeine intake. He had no family history of epilepsy and sudden unexpected cardiac or unexplained death. Past electrocardiogram (ECG) did not indicate any arrhythmias. During videophone with his friend, he noted his abrupt involuntary movements of the left extremities just before losing consciousness. Realizing that the situation was critical, his friend immediately called an ambulance. When the ambulance staff arrived approximately 10 min later, an automatic external defibrillator did not recommend defibrillation, and the patient was already under asystolic cardiac arrest. CPR was successful, and about $1 \mathrm{~h}$ later, the patient was transferred to our hospital.

On arrival, his blood pressure was 156/111 $\mathrm{mmHg}$, heart rate was 77 beats/min regularly, and body temperature was $34.7^{\circ} \mathrm{C}$. Physical examination revealed he was on an unconscious state (Japan Coma Scale 300) and limb extension position. The auscultation findings of the chest and lungs were determined normal, and no peripheral edema was noted.

ECG revealed sinus rhythm at a rate of 61 beats $/ \mathrm{min}$ and QTc of 0.417 with no QT prolongation. There were ST segment depression in leads I, II, and V3-V6 and ST segment elevation in lead aVR (Fig. 1). ECG revealed no left ventricular wall motion abnormality with an ejection fraction of $70 \%$. Doppler images revealed only a mild tricuspid regurgitation with a regurgitation gradient of $24 \mathrm{mmHg}$. An arterial blood gas analysis has demonstrated severe metabolic acidosis. The results of the laboratory tests performed on admission are presented in Table 1. Although his liver function was found impaired, fasting blood sugar and electrolyte levels remained normal. A urinary drug screening test and blood cultures on admission disclosed negative findings. Computed tomography revealed no abnormalities in the brain, lungs, heart, liver, pancreas, or spleen, except for bilateral kidney atrophy.

On admission, the patient suffered from repetitive tonic-clonic seizures after the intramuscular administration of diazepam. Thereafter, he was admitted to the intensive care unit, where he was subsequently administered with continuous intravenous propofol and dexmedetomidine infusion. His arteriovenous fistula was thrombosed due to the CPA, and hence a temporary catheter was immediately inserted followed by a continuous HD therapy and a ventilator for synchronized intermittent mandatory ventilation.

On the second day of hospitalization, brain magnetic resonance imaging (MRI) revealed no apparent high signal area in the diffusion-weighted image (DWI), and magnetic resonance angiography (MRA) also showed no large vessel occlusion (Fig. 2). The propofol and dexmedetomidine infusion treatments were discontinued on the following day, and he spontaneously recovered from unconsciousness and withdrew from ventilator support. During monitoring, his consciousness was maintained in an alert state, and no cardiac problem was detected. To determine the cause of the CPA, the patient underwent a thorough diagnostic workup. Interictal electroencephalogram (EEG) obtained on day 9 revealed multiregional sharp waves and spike and wave complex over

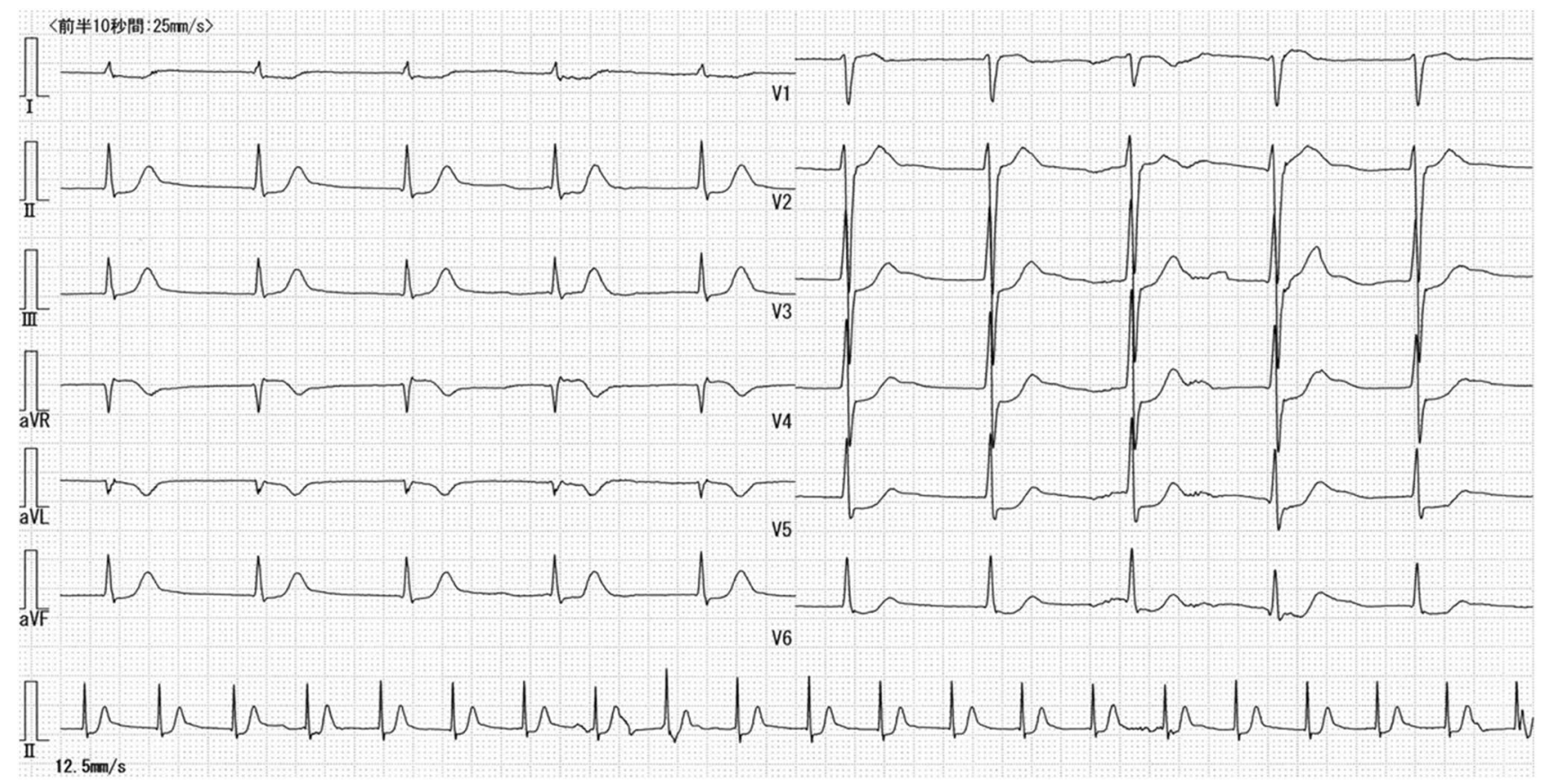

Fig. 1 Electrocardiographic (ECG) findings at the time of transport to the emergency room 
Table 1 Laboratory tests

\begin{tabular}{|c|c|}
\hline \multicolumn{2}{|c|}{ Blood coagulation test } \\
\hline WBC & $12.6 \times 10^{3} / \mu \mathrm{L}$ \\
\hline $\mathrm{RBC}$ & $4.21 \times 10^{6} / \mu \mathrm{L}$ \\
\hline $\mathrm{Hg}$ & $13.5 \mathrm{~g} / \mathrm{dL}$ \\
\hline $\mathrm{Ht}$ & $46.1 \%$ \\
\hline Plt & $270 \times 10^{3} / \mu \mathrm{L}$ \\
\hline PT & $9.6 \mathrm{~s}$ \\
\hline APTT & $26.5 \mathrm{~s}$ \\
\hline Fbg & $298 \mathrm{mg} / \mathrm{dL}$ \\
\hline FDP & $5.7 \mu \mathrm{g} / \mathrm{dL}$ \\
\hline D-dimer & $<1.0 \mu \mathrm{g} / \mathrm{mL}$ \\
\hline \multicolumn{2}{|c|}{ Blood chemistry test } \\
\hline $\mathrm{TP}$ & $6.9 \mathrm{~g} / \mathrm{dL}$ \\
\hline Alb & $4.4 \mathrm{~g} / \mathrm{dL}$ \\
\hline T-Bil & $0.3 \mathrm{mg} / \mathrm{dL}$ \\
\hline AST & $148 \mathrm{U} / \mathrm{L}$ \\
\hline ALT & $187 \mathrm{U} / \mathrm{L}$ \\
\hline $\mathrm{LDH}$ & $507 \mathrm{U} / \mathrm{L}$ \\
\hline$\gamma \mathrm{GTP}$ & $9 \mathrm{U} / \mathrm{L}$ \\
\hline Glucose & $156 \mathrm{mg} / \mathrm{dL}$ \\
\hline $\mathrm{HbA} 1 \mathrm{c}$ & $7.1 \%$ \\
\hline $\mathrm{CK}$ & $157 \mathrm{IU} / \mathrm{L}$ \\
\hline CK-MB & $38 \mathrm{IU} / \mathrm{L}$ \\
\hline BUN & $25 \mathrm{mg} / \mathrm{dL}$ \\
\hline $\mathrm{Cr}$ & $10.09 \mathrm{mg} / \mathrm{dL}$ \\
\hline $\mathrm{Na}$ & $146 \mathrm{mEq} / \mathrm{L}$ \\
\hline $\mathrm{K}$ & $3.2 \mathrm{mEq} / \mathrm{L}$ \\
\hline $\mathrm{Cl}$ & $104 \mathrm{mEq} / \mathrm{L}$ \\
\hline $\mathrm{Ca}$ & $9.3 \mathrm{mg} / \mathrm{dL}$ \\
\hline IP & $3.4 \mathrm{mg} / \mathrm{dL}$ \\
\hline CRP & $<0.09 \mathrm{mg} / \mathrm{dL}$ \\
\hline \multicolumn{2}{|c|}{ Arterial blood gas (room air) } \\
\hline $\mathrm{pH}$ & 7.25 \\
\hline $\mathrm{PO}_{2}$ & $86 \mathrm{mmHg}$ \\
\hline $\mathrm{PCO}_{2}$ & $45 \mathrm{mmHg}$ \\
\hline $\mathrm{HCO}_{3}^{-}$ & $12.3 \mathrm{mEq} / \mathrm{L}$ \\
\hline $\mathrm{BE}$ & $25.0 \mathrm{mEq} / \mathrm{L}$ \\
\hline Lac & $19 \mathrm{mEq} / \mathrm{L}$ \\
\hline
\end{tabular}

$W B C$ white blood cell, $R B C$ red blood cell, $H g$ hemoglobin, $H t$ hematocrit, Plt platelet, $P T$ prothrombin time, $A P T T$ activated partial thromboplastin time, $F b g$ fibrinogen, $F D P$ fibrin/fibrinogen degradation product, $T P$ total protein, $A l b$ albumin, $T$-Bil total bilirubin, $A S T$ aspartate aminotransferase, $A L T$ alanine aminotransferase, $L D H$ lactate dehydrogenase, $A L P$ alkaline phosphatase, $\gamma G T P \gamma$-glutamyl transpeptidase, $C K$ creatine kinase, $C K-M B$ creatine kinase myocardial band, $B U N$ blood urea nitrogen, $C R E$ creatinine, $N a$ sodium, $K$ potassium, $\mathrm{Cl}$ chloride, $\mathrm{Ca}$ calcium, $I P$ inorganic phosphorus, $C R P$ C-reactive protein, $B E$ base excess, Lac lactate

both hemispheres. The most active foci were located in the right frontal (F4, F8) regions (Fig. 3). Considering his medical history, symptoms, and clinical and laboratory findings, it would appear that the generalized tonic-clonic seizure associated with epilepsy caused the CPA. Then, the patient was subsequently started on levetiracetam for secondary prevention. Finally, he was discharged 16 days later without any complications.

\section{Discussion}

We describe the case of a patient who suffered from a CPA accompanied by a generalized tonic-clonic seizure. His cardiological workup revealed normal results. With no obvious cause and no other relevant preexisting conditions, the asystole could be attributed to epileptic seizure. We hypothesized that his seizure might have been associated with "near-SUDEP" (defined as a patient with epilepsy who survives resuscitation for more than $1 \mathrm{~h}$ after a cardiorespiratory arrest that has no structural cause identified after investigation) [11]. This would explain why he noted the seizure just before losing consciousness and had the abnormality found in his EEG.

SUDEP has been identified as one of the most frequent causes of death among patients with epilepsy. However, most of the cases are highly unrecognized and underreported as $90 \%$ of SUDEP cases are unwitnessed [12]. Therefore, the underlying pathophysiology remains incompletely understood. It has been well described that seizures can induce cardiac arrhythmias, leading to the hypothesis that SUDEP could be caused due to a cardiac mechanism [13]. The most common arrhythmia is sinus tachycardia, which accompanies $90 \%$ of all seizures [14]. Asystole is uncommon and can occur in approximately only $0.2 \%-0.5 \%$ of seizures [15]; this implies that the presence of ictal asystole could be associated with SUDEP [16]. Respiratory depression and apnea occurring during and after a seizure have also been well documented to explain the etiology of SUDEP, and these abnormalities can develop severe obstructive apnea and pulmonary congestion or edema, ultimately resulting in CPA. It is unclear whether the present patient's seizure-related asystole accompanied the occurrence of the seizure or whether it was secondary to apnea-related hypoxia because this was a prehospital emergency case. On the other hand, SUDEP is found to be generally unwitnessed, but when witnessed, most of the studies have reported that the patients' seizure type is generalized tonic-clonic as in the present case [17]. The MORTEMUS study has described that the peculiar pattern of cardiorespiratory arrest in patients with SUDEP is the alteration of severe cardiorespiratory function, which often leads to death immediately after a generalized tonic-clonic seizure [18].

The relationship between SUDEP and end-stage renal disease (ESRD) remains to be poorly understood. However, epilepsy and chronic kidney disease (CKD) are common 

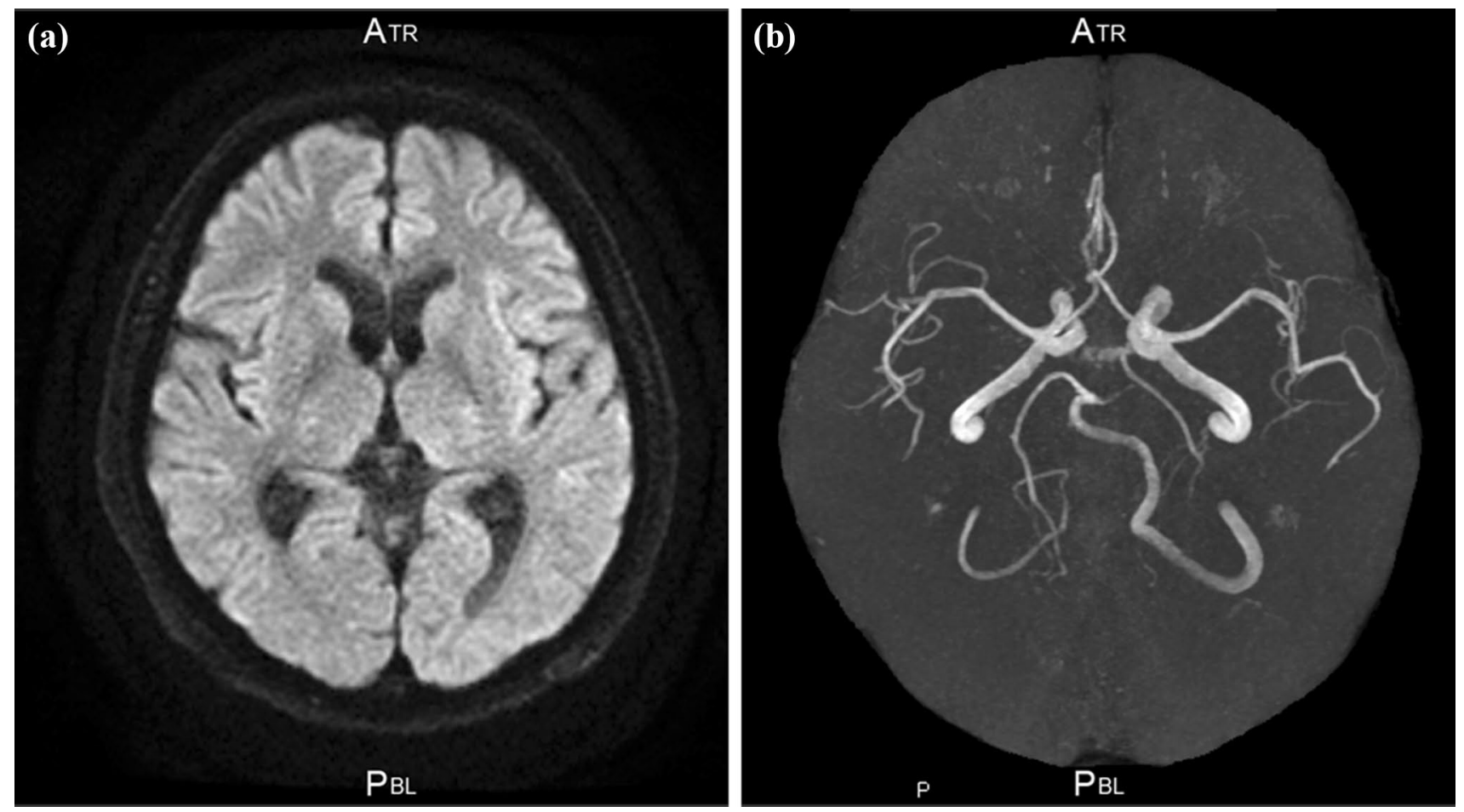

Fig. 2 Brain magnetic resonance imaging (MRI) on day 2 Brain magnetic resonance imaging (MRI) revealed no apparent high signal area in the diffusion-weighted image (DWI) (a), and magnetic resonance angiography (MRA) showed no large vessel occlusion (b)

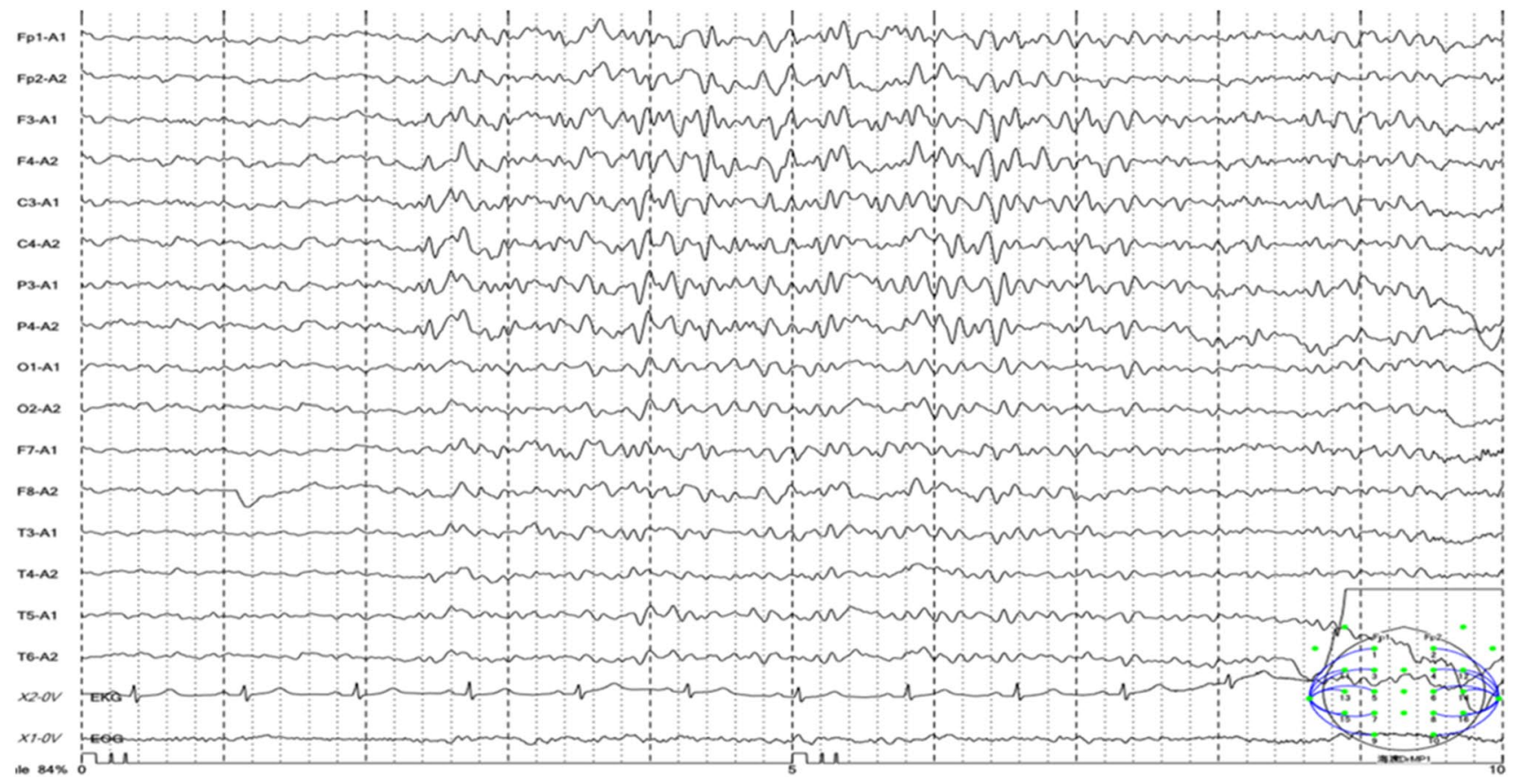

Fig. 3 Electroencephalogram (EEG) on day 9 Electroencephalogram (EEG) revealed multiregional sharp waves and spike and wave complex over both hemispheres. The most active foci were located in the right frontal (F4, F8) regions

chronic disorders with high mortality rates, and in general HD patients and people with epilepsy are at an increased risk for SD [10]. The incidence of seizure has been reported to be approximately $10 \%$ in patients with CKD [19], and 
HD-associated seizure has been considered as a complication in HD patients. HD-associated seizure occurs in $7 \%-50 \%$ of patients with ESRD [20]. In parallel, the incidence of SD in patients with CKD or ESRD is reported to be high. Anemia, diabetes, ischemic disease, and acid-base disorders are known to contribute to the increased vulnerability to SD in these patients [21]. Therefore, it appears reasonable to assume that there would be more cases of SUDEP in patients with CKD or ESRD. However, it is important to note that SUDEP appears to be rare in patients with ESRD. Gomes RA et al. retrospectively reported that SUDEP events were found in 5 of 209 patients on HD. They concluded that SUDEP is a rare event in people with ESRD [22].

There are also few case reports in which patients on HD developed CPA due to SUDEP. In this present case, some findings to explain the causal relationship. First, the patient's condition had been stable at the clinic. In HD patients, SD could be induced by various factors such as the presence or history of cardiovascular disease, the problem of fluid volume, electrolyte disorder, and sympathetic overactivity [23]. Thus, the onset of SD is determined to be most common in the first year or approximately 10 years after HD initiation $[3,24]$. The increased SD rate would be due to the increased volume and potassium accumulated over a longer weekend interval [25]. In fact, our patient received treatment the previous day (on Tuesday), and there was no risk for SD according to his laboratory and image data on admission. His ECG and echocardiography also revealed normal findings. Second, the patient had a witnessed generalized tonic-clonic seizure and progressed to CPA caused by asystole. In fact, cardiac arrest was recognized only by his friend; hence, it was unclear whether it was a real seizure. The repeated seizures identified during his hospitalization could be explained by post-cardiac arrest syndrome. However, he told his friend that his left arm moved by itself, after which he convulsed and lost consciousness. EEG demonstrated multidomain sharp waves and spike-wave complexes, primarily in the right frontal region (F4, F8), which were well consistent with epilepsy. Furthermore, his EEG revealed abnormalities despite good neurological recovery after successful resuscitation. Therefore, we speculated that this was a case of seizure-induced asystole and near-SUDEP.

SUDEP is considered as a SD that occurs in well-situated patients with epilepsy. Risk factors for SUDEP include (i) high seizure frequency, (ii) presence of tonic-clonic seizures, (iii) multiple use of antiepileptic drugs, (iv) frequent changes in medications, (v) neglect or abrupt discontinuation of medications, (vi) lack of nocturnal surveillance, (vii) long duration of illness, (viii) young adult age, and (ix) male sex; however, these factors remain controversial [26]. It was not clear if this patient satisfied the near-SUDEP definition because the patient had no history of epilepsy. In other previous case reports, most patients with SUDEP suffered from chronic, intractable seizures that are uncontrollable and of relatively long duration despite the use of antiepileptic drugs [27]. In rare case, the patient with near-SUDEP had no history of epileptic seizures and only reported of the inability to sleep well due to a burning sensation in the foot [28]. Therefore, it can be speculated that SUDEP can occur early in the course of epilepsy or even in patients with few seizures.

It is also unclear whether the cause of cardiac arrest in the present patient was due to the cause of SD in type 1 diabetes. There are five categories of causes of sudden death in type 1 diabetes: (1) ketoacidosis, (2) hypoglycemic brain damage, (3) autonomic neuropathy, (4) dead in bed syndrome, and (5) unknown causes $[29,30]$. Although autonomic neuropathy could not be ruled out as the cause of cardiac arrest in this case, there were no episodes of orthostatic hypotension or prolonged QT duration on ECG. Therefore, the clinical course of the case suggests that the patient had cardiac arrest due to the seizure and developed a condition similar to near-SUDEP.

Coronary angiography should certainly be performed to exclude coronary artery disease in such a case. However, we did not perform coronary angiography in this patient because his general and cardiac condition was good. Moreover, there was no enzymatic and echocardiographic evidence of myocardial infarction in our patient. Hence, we did not perform coronary angiography.

We support the recommendations to maintain a heightened suspicion for SUDEP in SD among patients on HD. Both dialysis patients and people with epilepsy have extraordinarily high mortality rates and increased risk for SD. In the absence of cardiac abnormalities, we recommend combined ECG and EEG monitoring in patients with cardiorespiratory arrest. We have also confirmed that obtaining information on the management of seizures in patients with CKD and the possibility of SUDEP occurrence among patients with ESRD is a must.

\section{Declaration}

Conflict of interest The authors have declared that no conflict of interest exists.

\section{References}

1. Saran R, Robinson B, Abbott KC, et al. US renal data system 2019 annual data report: epidemiology of kidney disease in the United States. Am J Kidney Dis. 2020;75:A6-7.

2. Moroi M, Tamaki N, Nishimura M, et al. Association between abnormal myocardial fatty acid metabolism and cardiac-derived death among patients undergoing hemodialysis: results from a cohort study in Japan. Am J Kidney Dis. 2013;61:466-75.

3. Hiyamuta $\mathrm{H}$, Tanaka $\mathrm{S}$, Taniguchi $\mathrm{M}$, et al. The incidence and associated factors of sudden death in patients on hemodialysis: 
10-year outcome of the Q-Cohort study. J Atheroscler Thromb. 2020;27:306-18.

4. Joki N, Tanaka Y, Hayashi T. Sudden death, a common cause of death in Japanese hemodialysis patients. J Atheroscler Thromb. 2020;27:303-5.

5. Bleyer AJ, Hartman J, Brannon PC, Reeves-Daniel A, Satko SG, Russell G. Characteristics of sudden death in hemodialysis patients. Kidney Int. 2006;69:2268-73.

6. Nashef L. Sudden unexpected death in epilepsy: terminology and definitions. Epilepsia. 1997;38(11 Suppl):S6-8.

7. Sander JW, Bell GS. Reducing mortality: an important aim of epilepsy management. J Neurol Neurosurg Psychiatry. 2004;75:349-51.

8. Sveinsson O, Andersson T, Carlsson S, Tomson T. The incidence of SUDEP: A nationwide population-based cohort study. Neurology. 2017;89:170-7.

9. Tomson T, Sveinsson O, Carlsson S, Andersson T. Evolution over time of SUDEP incidence: A nationwide population-based cohort study. Epilepsia. 2018;59:e120-4.

10. Scorza FA, Scattolini M, Cysneiros RM, et al. Sudden unexpected death in patients with epilepsy receiving renal replacement therapy with dialysis: a 17-year experience at a single institution. Hemodial Int. 2010;14:364-9.

11. Nashef L, So EL, Ryvlin P, Tomson T. Unifying the definitions of sudden unexpected death in epilepsy. Epilepsia. 2012;53:227-33.

12. Elmali AD, Bebek N, Baykan B. Let's talk SUDEP. Noro Psikiyatr Ars. 2019;56:292-301.

13. Massey CA, Sowers LP, Dlouhy BJ, Richerson GB. Mechanisms of sudden unexpected death in epilepsy: the pathway to prevention. Nat Rev Neurol. 2014;10:271-82.

14. Zijlmans M, Flanagan D, Gotman J. Heart rate changes and ECG abnormalities during epileptic seizures: prevalence and definition of an objective clinical sign. Epilepsia. 2002;43:847-54.

15. Schuele SU, Bermeo AC, Alexopoulos AV, et al. Video-electrographic and clinical features in patients with ictal asystole. Neurology. 2007;69:434-41.

16. Winesett P, Feliciano CA, Tatum WO. Temporal lobe seizures triggering recurrent syncope by ictal asystole. Epilepsy Behav. 2009; 14:258-60.

17. Tomson T, Walczak T, Sillanpaa M, Sander JW. Sudden unexpected death in epilepsy: a review of incidence and risk factors. Epilepsia. 2005;46(Suppl 11):54-61.
18. Ryvlin P, Nashef L, Lhatoo SD, et al. Incidence and mechanisms of cardiorespiratory arrests in epilepsy monitoring units (MORTEMUS): a retrospective study. Lancet Neurol. 2013;12:966-77.

19. Bergen DC, Ristanovic R, Gorelick PB, Kathpalia S. Seizures and renal failures. Int J Artif Organs. 1994;17:247-51.

20. Sonmez F, Mir S, Tutuncuoglu S. Potential prophylactic use of benzodiazepines for hemodialysis-associated seizures. Pediatr Nephrol. 2000;14:367-9.

21. Pun PH, Smarz TR, Honeycutt EF, Shaw LK, Al-Khatib SM, Middleton JP. Chronic kidney disease is associated with increased risk of sudden cardiac death among patients with coronary artery disease. Kidney Int. 2009;76:652-8.

22. Gomes RA, Kesrouani S, Cruz J, et al. Is there something special about cardiovascular abnormalities and sudden unexpected death in epilepsy among patients with chronic renal insufficiency in regular hemodialysis program? Arq Neuropsiquiatr. 2009;67:209-13.

23. Makar MS, Pun PH. Sudden cardiac death among hemodialysis patients. Am J Kidney Dis. 2017;69:684-95.

24. Eckardt KU, Gillespie IA, Kronenberg F, et al. High cardiovascular event rates occur within the first weeks of starting hemodialysis. Kidney Int. 2015;88:1117-25.

25. Bleyer AJ, Russell GB, Satko SG. Sudden and cardiac death rates in hemodialysis patients. Kidney Int. 1999;55:1553-9.

26. Hesdorffer DC, Tomson T, Benn E, et al. Combined analysis of risk factors for SUDEP. Epilepsia. 2011;52:1150-9.

27. Devinsky O. Sudden, unexpected death in epilepsy. N Engl J Med. 2011;365:1801-11.

28. Seo MH, Sung WY. A case of near-sudden unexpected death in epilepsy due to ventricular fibrillation. Open Access Emerg Med. 2019;11:161-6.

29. Tattersall RB, Gill GV. Unexplained deaths of type 1 diabetic patients. Diabet Med. 1991;8:49-58.

30. McNally PG, Lawrence IG, Panerai RB, et al. Sudden death in type 1 diabetes. Diabetes Obes Metab. 1999;1:151-8.

Publisher's Note Springer Nature remains neutral with regard to jurisdictional claims in published maps and institutional affiliations. 